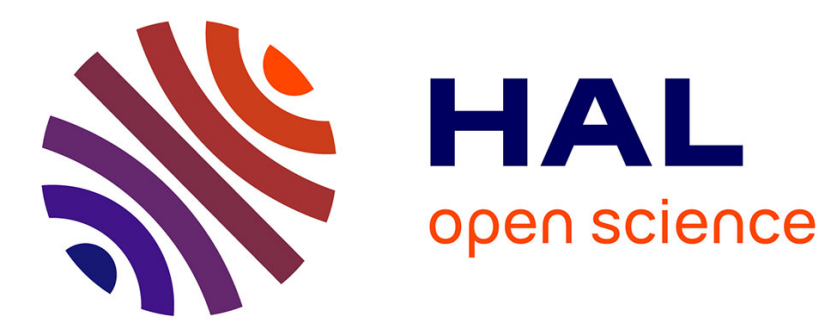

\title{
Patient-Hospital Communication: a Platform to Improve Outpatient Chemotherapy
}

Guillaume Lamé, Oualid Jouini, Julie Stal-Le Cardinal, Muriel Carvalho, Christophe Tournigand, Pierre Wolkenstein

\section{- To cite this version:}

Guillaume Lamé, Oualid Jouini, Julie Stal-Le Cardinal, Muriel Carvalho, Christophe Tournigand, et al.. Patient-Hospital Communication: a Platform to Improve Outpatient Chemotherapy. Winter Simulation Conference, Dec 2016, Arlington, VA, United States. hal-01416061

\section{HAL Id: hal-01416061 https://hal.science/hal-01416061}

Submitted on 14 Dec 2016

HAL is a multi-disciplinary open access archive for the deposit and dissemination of scientific research documents, whether they are published or not. The documents may come from teaching and research institutions in France or abroad, or from public or private research centers.
L'archive ouverte pluridisciplinaire HAL, est destinée au dépôt et à la diffusion de documents scientifiques de niveau recherche, publiés ou non, émanant des établissements d'enseignement et de recherche français ou étrangers, des laboratoires publics ou privés.

\section{(1)(1) $\$(0)$}

Distributed under a Creative Commons Attribution - NonCommercial - ShareAlikel 4.0 


\title{
PATIENT-HOSPITAL COMMUNICATION: A PLATFORM TO IMPROVE OUTPATIENT CHEMOTHERAPY
}

\author{
Guillaume Lamé, Oualid Jouini, \\ Julie Stal-Le Cardinal \\ Laboratoire Genie Industriel \\ CentraleSupélec, Université Paris-Saclay \\ Grande Voie des Vignes \\ 92290 Chatenay-Malabry, FRANCE
}

Christophe Tournigand

Department of Medical Oncology

Hôpital Henri Mondor, APHP

51, avenue du Maréchal de Lattre de Tassigny

94010 Créteil, FRANCE

\author{
Muriel Carvalho \\ Pharmacy Department \\ Hôpital Henri Mondor, APHP \\ 51, avenue du Maréchal de Lattre de Tassigny \\ 94010 Créteil, FRANCE
}

Pierre Wolkenstein

Department of Dermatology

Hôpital Henri Mondor, APHP

51, avenue du Maréchal de Lattre de Tassigny

94010 Créteil, FRANCE

\begin{abstract}
We apply Discrete Event Simulation (DES) to a system of two strongly interconnected departments, an outpatient oncology clinic for chemotherapy delivery, and the pharmacy unit that prepares the chemotherapy drugs. The model is developed in close collaboration with the French hospital Henri Mondor, and is validated using real data. The objective is to identify sources of patient waiting times in the outpatient oncology clinic and to identify relevant corrective actions. We show that the coordination between the two departments is the key barrier to higher performance. Solutions are proposed based on increased information sharing and obtaining advanced information on patient status, to allow advanced drug preparation. A two-phase project for improvement is proposed. This paper contributes to the literature on multi-department simulation, which is still rare in healthcare OR compared to onedepartment studies.
\end{abstract}

\section{INTRODUCTION}

The number of Americans alive with a history of cancer is expected to increase from 14.5 million in 2014 to 19 million by 2024 (DeSantis et al. 2014). The cost of ambulatory cancer care in the US is already rising fast: from $\$ 25.5$ billion in 2001 to $\$ 43.8$ billion in 2011 (Soni 2014). Yet even if the number of patients increases, costs need to be contained. Healthcare systems have to face this challenge by gaining efficiency in treatment. Besides, with such numbers of patients, service quality is becoming a key notion.

Outpatient chemotherapy is one of the main options for curing cancer. Every year, about 650,000 American cancer patients receive outpatient chemotherapy (Halpern and Yabroff 2008). Despite this activity, outpatient chemotherapy clinics are often far from optimal efficiency. For instance, studies have reported that patients wait 72.7 minutes from check-in to treatment at the University of Texas MD Anderson Cancer Center (Kallen et al. 2012), 97 minutes in 11 French clinics (Debreuve-Theresette et al. 2015). For these patients, waiting time at the outpatient clinic is an important factor of dissatisfaction 


\section{Lamé, Jouini, Stal-Le Cardinal, Carvalho, Tournigand, and Wolkenstein}

(Lis, Rodeghier, and Gupta 2009). Besides, it generates distress and has undesirable emotional impact (Catania et al. 2011). It is also an operational issue, as a patient waiting is still consuming resources: nurse attention, treatment chair, etc. On both the clinical and the operational dimensions, waiting time in outpatient chemotherapy is a problem.

Depending on the hospital, many factors may contribute to waiting times, for example poor patient scheduling resulting in overwhelmed nurses. However, in some cases, the problem does not come from the oncology department itself but from another service: the pharmacy. In these cases, patients wait for their chemotherapy drugs rather than for available nurses. To solve this problem, one solution is to have patients come one day for their doctor examination and come back the next day for chemotherapy (Dobish 2003). It implies that patients have to come two days in a row and it also doubles transportation costs. Thus many patients do not like this option (Lau, Watson, and Hasani 2014). Another way forward is advanced drug preparation (Masselink et al. 2012). However, chemotherapy drugs are expensive. Therefore pharmacists have developed ways to reduce the risk that a preparation will be wasted if the patient is not in shape to receive it on her chemotherapy day. Many of these methods are based on increased communication with patients. Mobile apps are developed, and well accepted by patients, for instance to manage chemotherapy toxicity (McCann et al. 2009). Phone call platforms are created to gather information on patient's status, to avoid side effects leading to unscheduled hospitalizations (Coriat et al. 2012) but also to recover patient data before treatment, which allows to prepare chemotherapy drugs in advance and reduces waiting times (Scotté et al. 2013).

As promising as they may be, such communication systems are costly, and in the current economic context hospital managers want to have quantitative elements before investing. To the best of our knowledge no Operations Research/Operations Management (OR/OM) study has analyzed prospectively the impact of such communication platforms in oncology. Moreover, published studies provide pre-post data but their methods don't allow them to compare the impact of a phone call platform to other measures such as additional staffing or modified work schedules. Yet these are the solutions healthcare managers naturally come up with, so it is important that they can be evaluated and discarded if they are suboptimal.

In this article, we show that advanced chemotherapy drug preparation is a highly effective solution to patient waiting time compared to other more traditional measures. We use Discrete Event Simulation to evaluate different scenarios and demonstrate that advanced preparation has the strongest potential for improving patient waiting times. Advanced chemotherapy drug preparation is made possible by the availability of information on patient's status which reduces the risk to prepare drugs for a patient who won't be fit to receive them. To gather this information, a platform for calling patients before their chemotherapy day is proposed.

This approach is original compared to previous works in OR/OM as it considers the outpatient oncology clinic and the pharmacy as an integrated system (Lamé, Jouini, and Stal-Le Cardinal 2016). To improve outpatient chemotherapy efficiency, one can improve these two departments independently. Patient planning and scheduling, medical planning or staffing and resource levels can be analyzed and optimized in the outpatient clinic. In the pharmacy, scheduling of drug production can be improved. However, these are traditional ways to consider the problem. They contribute to the more general situation that most OR/OM studies in healthcare are unit-specific and models encompassing more than one department are rare (Gunal and Pidd 2010). This is in contradiction with the fact that hospitals have long been described as complex systems, and in such systems interactions between the parts are often as important as the parts themselves in the behavior of the system.

The present study is an example where working at a multi-department level and enhancing coordination through adequate information gathering and sharing improves significantly the overall system's performance. Different solutions are compared and the ones based on increased patient-hospital communication prove to be cost-efficient and effective. This is an example of how information technology can be used in a creative way to improve patient flows. We go as far as to discuss implementation details and integration in the existing system. 


\section{Lamé, Jouini, Stal-Le Cardinal, Carvalho, Tournigand, and Wolkenstein}

In Section 2, Henri Mondor hospital is presented, as well as the care process for outpatient chemotherapy. In Section 3, the various scenarios for improvement that could be identified in the literature or were proposed by managers are discussed. In Section 4 they are evaluated using a Discrete Event Simulation model. This evaluation shows the superiority of advanced preparation compared to other options. The way to increase advanced preparation is analyzed. In Section 5 implementation is discussed. The article ends with some concluding remarks.

\section{SETTING AND CARE PROCESS}

Henri Mondor hospital is a public university hospital in Créteil, near Paris, France. It has 1,300 beds and 120 day-hospital spots. In 2009, around 240,000 consultations, 30,000 inpatient days and 45,000 outpatient sessions took place in this hospital. Henri Mondor hospital employs 4,000 people, and it has three expert centers in oncology, for urology, hematology and digestive cancers.

The oncology department is divided between outpatient and inpatient units. Around 4,000 outpatient chemotherapy sessions take place every year in the outpatient unit. All cytotoxic drug preparations take place in a centralized pharmaceutical unit which prepares chemotherapies for all departments which request it. The global trend is an increase of the number of patients and drug preparations: $+10 \%$ drug preparations and $+19 \%$ outpatient oncology sessions between the first semesters of 2014 and 2015 .

In this context, the head of the oncology department worries that his patients are waiting a lot when they come for a chemotherapy. This is a double problem. First, waiting time is a factor of patient dissatisfaction (Lis, Rodeghier, and Gupta 2009). Second, patients who are waiting consume resources. They usually occupy treatment seats and they need nurse attention. Therefore waiting time is problematic as it prevents higher patient turnover. The objective of the project, which involves members of the oncology department, of the pharmacy and of an OR/OM research team, is to identify the most efficient actions to reduce waiting times, with a coordinated view of the patient/chemotherapy circuit.

Figure 1 shows the care process for outpatient chemotherapy prescription, preparation and administration at Henri Mondor hospital. Interviews in other hospitals showed that this process is standard in its structure. Two different flows are synchronized: a patient flow in the outpatient clinic, and a drugs flow coming from the pharmacy. On her chemotherapy day, the patient checks in, waits for her examination, she is examined by an oncologist, and if the doctor validates the chemotherapy she goes to the treatment room. There, her drip is set up, and as soon as the drugs arrive injection can start. If the doctor decides that the patient is not fit for treatment (roughly 10\% of patients, congruent with (Masselink et al. 2012) and confirmed by interviews in other hospitals) then she checks out and goes home. The only exception to that process is a small proportion of patients, around 10\%, who do not see the oncologist and go to the treatment room right after checking in. Waiting times occur before medical consultation (24 minutes on average) and between the end of the consultation and the beginning of chemotherapy treatment (1 hour on average).

Concerning chemotherapy drugs preparation, the process is an industry standard. A preparation file is printed, the components are kitted and sent to an isolator in batches of four kits. The batch is sterilized. Then all four preparations can be mixed and are sterilized when they are sent out of the isolator. The drugs are controlled, packed and made available to a logistician. In the morning, this logistician takes the drugs to a counter where nurses come to take them. In the afternoon, the logistician brings them to the oncology department. Transportation is important as two units are located 9 floors away from each other.

A major element is the connection between patient flow and pharmacy flow. Some drugs are eligible to advanced preparation and some are not (the most expensive or unstable ones). For the drugs that can be prepared in advance, the pharmacy waits for a confirmation based on blood test results, performed two days before chemotherapy. Preparation is started as soon as positive blood tests results are received and validated by an oncologist. For drugs that can't be prepared in advance, because they are too expensive or have too short stability delays, the oncologist confirms only after seeing the patient on chemotherapy day. This preparation policy has obviously a great impact on patient waiting times. 
Lamé, Jouini, Stal-Le Cardinal, Carvalho, Tournigand, and Wolkenstein

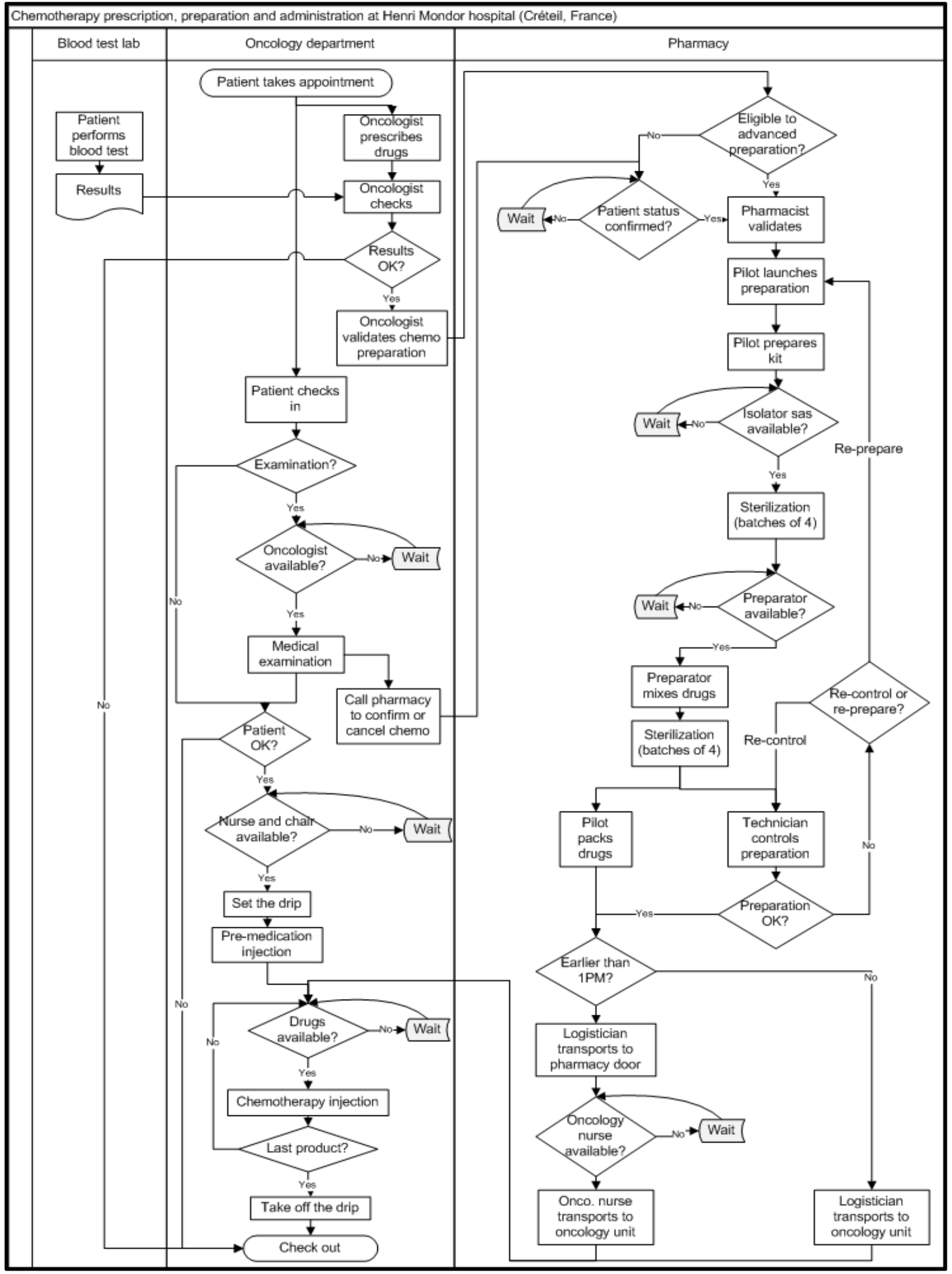

Figure 1: Process for outpatient chemotherapy. 


\section{Lamé, Jouini, Stal-Le Cardinal, Carvalho, Tournigand, and Wolkenstein}

In Henri Mondor hospital, $84 \%$ of preparations are eligible to advanced preparation. However, on average only $25 \%$ of the chemotherapy drugs administered on week days are effectively prepared before the day of administration. Observation sessions in the outpatient chemotherapy clinic showed that the main cause of waiting times is waiting for chemotherapy products: patients are here, nurses and chairs are available, but the drugs have not been delivered in the service (whether it be because they are in preparation or in transit between the pharmacy and the outpatient clinic).

\section{REFLECTION ON POTENTIAL SOLUTIONS}

When confronted with this issue of patient waiting times due to late chemotherapy drugs delivery, different options are available. One could try to increase manpower or organize it differently. Work schedules in the pharmacy and the oncology unit could have an impact. For example, the pharmacy could start working earlier in the morning and the outpatient unit later, which would give more time ahead to the pharmacy to prepare drugs in advance. Staff could be added at different steps of the process: production pilots or pharmaceutical assistants in the pharmacy, nurses in the oncology unit, logisticians to organize more frequent deliveries between the two units. Some hospitals have also created algorithms to optimize drug preparation scheduling in the pharmacy (Mazier, Billaut, and Tournamille 2010).

However, the impact of these solutions on chemotherapy drug availability is uncertain. Shifting schedules is a free solution but it can only give one or two hours to the pharmacy to prepare a few drugs in advance. Adding resources at one stage or the other is expensive, and it won't solve the problem that without information on patient status (today, blood test results for all preparations and medicine confirmation after examination for prescriptions that are not eligible to advanced preparation), the pharmacy cannot do anything. The same is true for online pharmacy scheduling optimization, which will reduce pharmacy lead times but whose impact compared to advanced preparation is unsure.

Obtaining the right information about the patient and her prescription at the right time is crucial to drug preparation. Today, oncology nurses are in charge of gathering blood test results from external labs. This is made difficult by the fact that almost each patient has a different lab, and some are cooperative (i.e. they fax results as soon as they get them) whereas for others nurses have to call and remind them that results must be sent to the hospital. Besides, the pharmacy won't rely solely on blood test results to prepare expensive, unstable preparations, for which the financial risk is high if the intended patient is not sufficiently physically fit to get the drug.

An interesting approach is to apply Make-To-Stock (MTS) preparation with rounded doses. Normally, chemotherapy drug doses are prescribed depending on the body surface of the patient. Therefore there is a continuum of possible doses. To simplify production, some hospitals have decided to accept a limited deviation from the doses defined according to that formula and to practice "dose banding". Standard doses are defined, and when the oncologist prescribes a certain dose, the pharmacist actually prepares the closest standard dose, according to an agreement established with the oncologist (for example, the agreement can say that "for product X, for all doses between $170 \mathrm{mg}$ and $180 \mathrm{mg}$ the prepared dose will be $175 \mathrm{mg}$ "). If the patient is not fit to receive her drugs, then it is easier to reallocate this dose to a patient with a prescription in the same range. However, the definition of doses is still a blurry issue. Moreover, feedback from other hospitals shows that this practice is especially interesting for products with a high turnover, for which reallocation is easy. Our hospital has a wide patient-mix and a limited flow of patients. Besides, preparing MTS drugs would require storage space which is not available today. As a consequence this option is not evaluated here.

Considering all these elements, a promising solution concept would be one that could provide the pharmacy with early information on patient status. Thus preparation could be started for drugs which are eligible to advanced preparation, and if the information is sufficiently robust the list of eligible products could be extended because this information reduces the risk that the patient is too sick to receive her treatment. One principle is to create a communication platform between the hospital and oncology outpatients. This platform would gather information prior to their coming for chemotherapy. The exact 
form of this platform is undetermined at this stage: it must first be proved that enhancing advanced preparation is superior to other solutions.

\section{EVALUATION OF THE IMPACT OF ADVANCED PREPARATION}

To evaluate different scenarios, a Discrete Event Simulation model is developed using Arena software from Rockwell Automation and based on the conceptual model of Figure 1. In the model a simulation replication corresponds to one working day. This is coherent with the real system, an outpatient clinic where a working day starts at $8 \mathrm{AM}$ and finishes at 6PM, and a pharmacy unit working from 8.30AM to 4.30PM. All resources are modelled: nurses, treatment chairs, oncologists, isolators for drug preparation, pharmaceutical assistants and transportation staff.

The issue of data collection is well-known in healthcare. In our case, arrival data is gathered from the appointment-management software with 18 months data. Drug production data is taken from the prescription-management software with 18 months data. For processing times, no database is available so we performed time studies (11 observation sessions in the outpatient clinic, 6 in the pharmacy), interviews ( 3 with the head of the oncology department, 3 with pharmacists) and review meetings to present intermediate results ( 2 with pharmacy and oncology managers, 1 with the oncology unit staff).

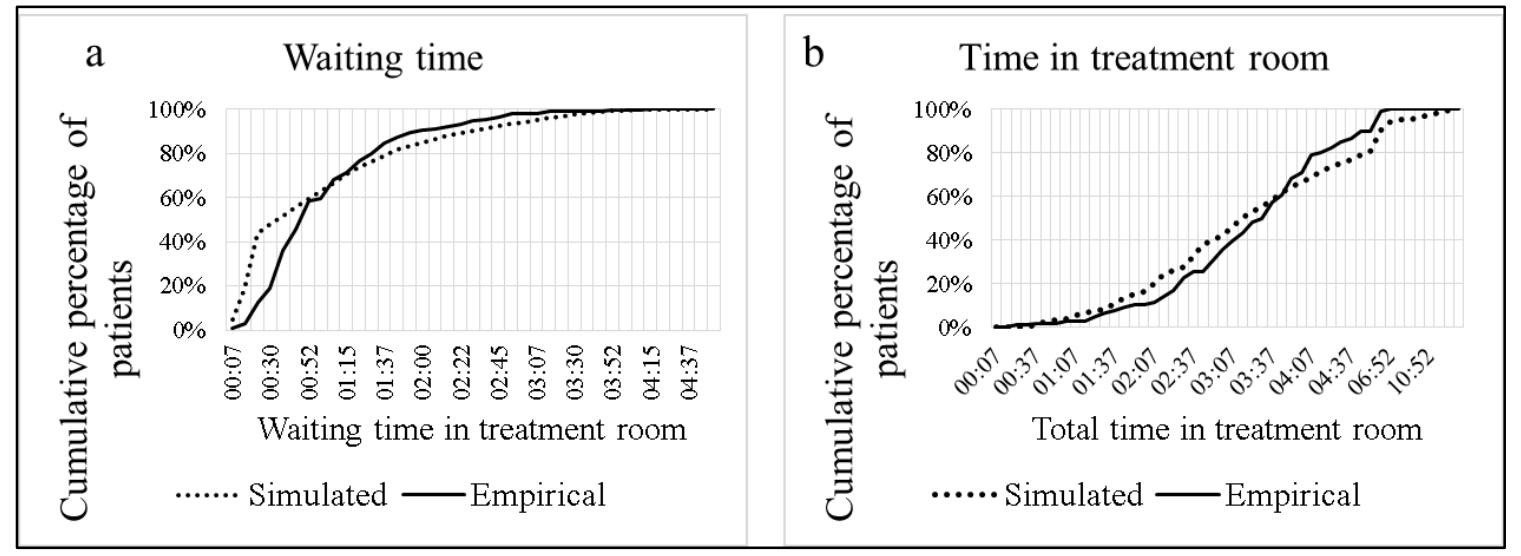

Figure 2: Cumulative distributions for waiting time (a) and time in treatment room (b).

We follow Sargent's procedure (Sargent 2013) for model validation. Figure 2 presents cumulative distributions for waiting time and time in treatment room, and compares simulation (700 replications) with empirical values. We aim at understanding the behavior of the system rather than fine-tuning it, therefore the curves are close enough to give confidence that the model is accurate for our purpose. In our model, one observation is one day in the outpatient clinic.

Figure 3 presents distribution indicators for patient waiting times under different scenarios with 100 replications for each scenario. Experiments showed that going further did not change the behavior or the compared performance of the scenarios. Scenarios are built along three dimensions: the level of resources and their organization, the proportion of products eligible to advanced preparation, and the quantity of eligible products that are effectively prepared in advance. The average situation today is that $84 \%$ of the preparations are eligible to advanced preparation, but only $25 \%$ of these are effectively prepared in advance. We also include two scenarios with $10 \%$ advanced preparation to test the impact of this parameter.

Results on Figure 3 clearly show that two measures have a clear impact on waiting times: adding a person for drug transportation on mornings (scenario "T"), and increasing advanced preparation. Another interesting insight is that the median remains almost stable for all scenarios, while the third quartile $(75 \%$ of the patients wait less than this value) and the $9^{\text {th }}$ decile ( $90 \%$ of the patients wait less than this value) 
are more helpful indicators. The long tail between third quartile and ninth decile is due to the $16 \%$ of products that are prepared only after the patient has seen the oncologist.

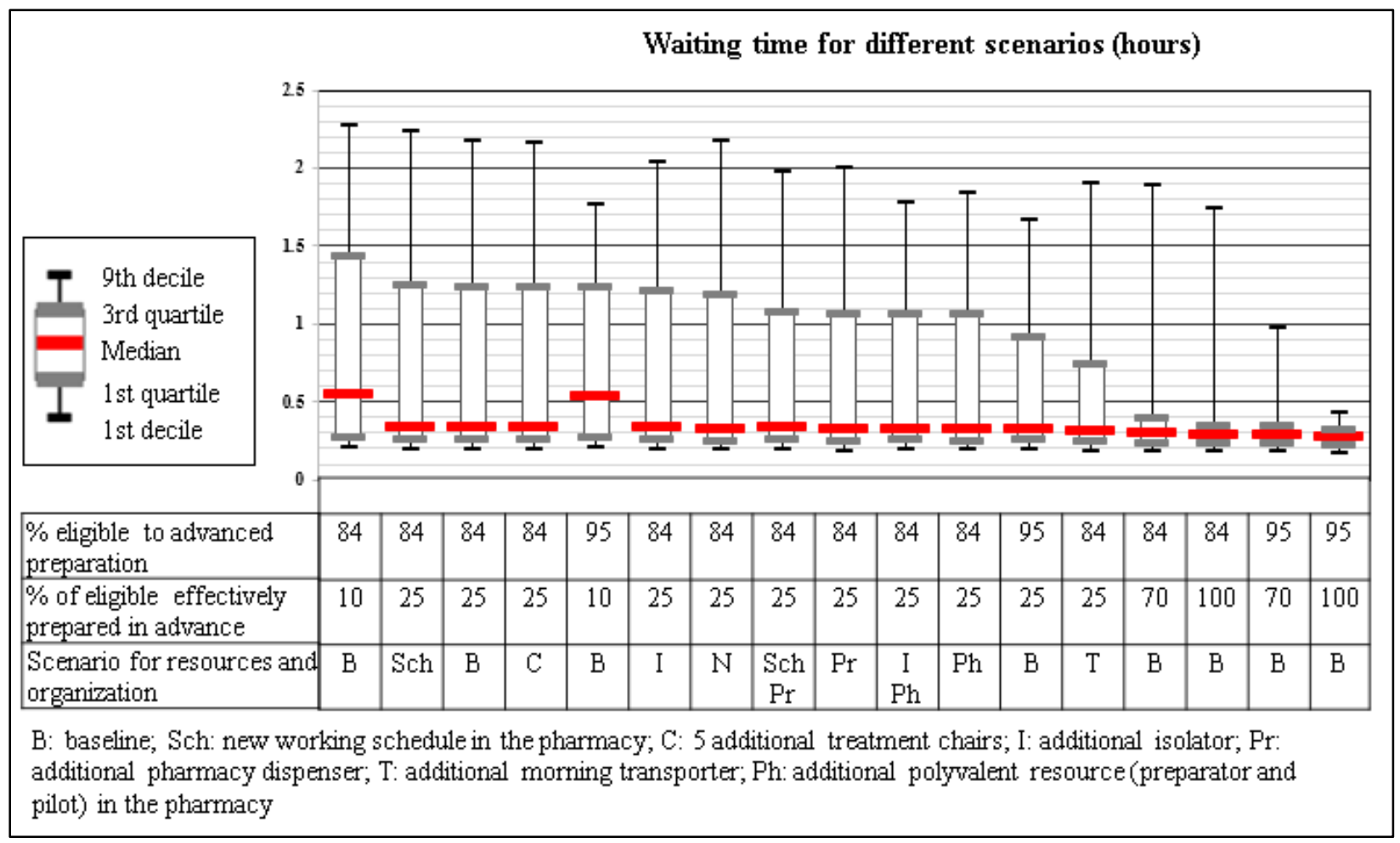

Figure 3: Evaluation of scenarios.

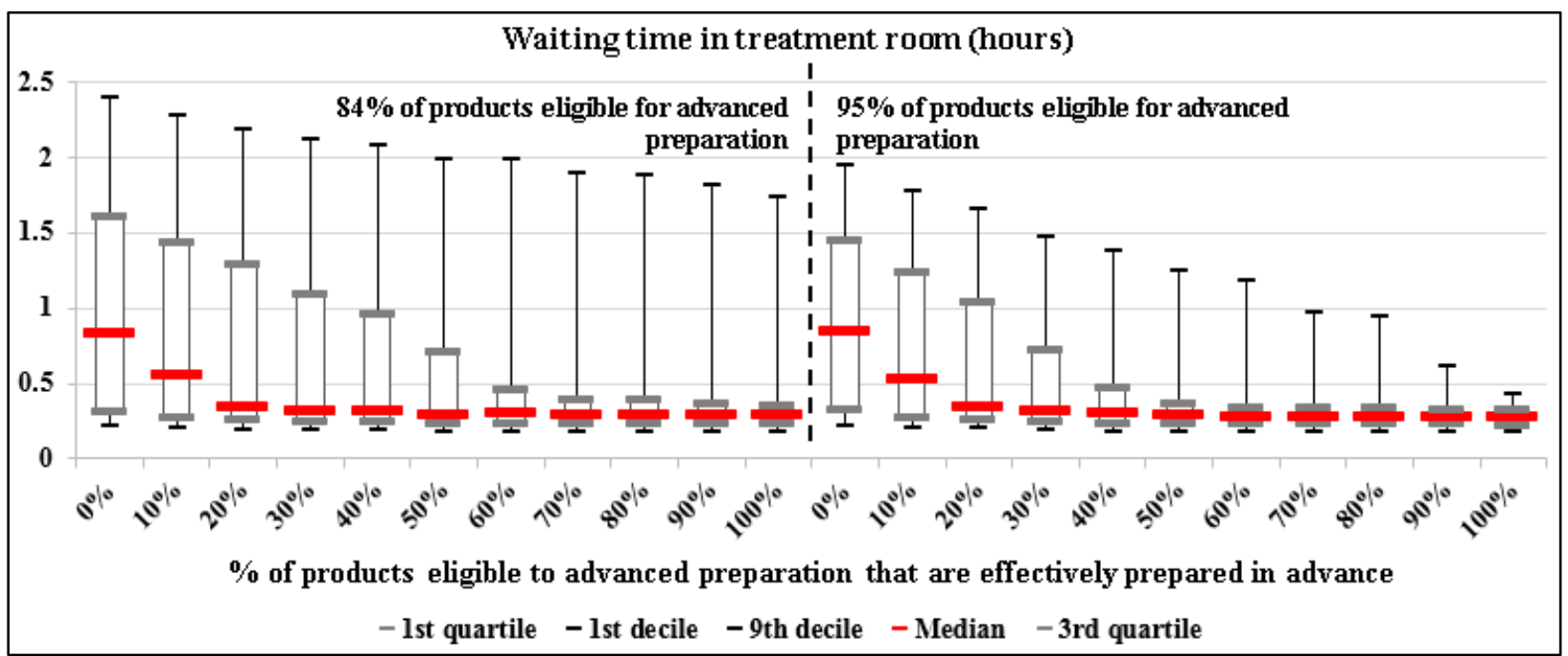

Figure 4: Waiting times for advanced preparation $0-100 \%$ and share of eligible products $84 \%$ and $95 \%$.

Figure 4 goes into more detail on the effect of different levels of advanced preparation. It appears that given a list of eligible products, increasing advanced preparation reduces waiting time down to a threshold of 20 minutes. This is the time needed for nurses to perform the administrative part (checking in on the IT system, checking the patient's documents) and setting the drip. Therefore if we want to reduce this duration we will have to look at the work content of nurses. 
The more products are eligible to advanced preparation, the sooner this threshold is reached. It is clear that the more drugs are prepared in advance, the lower waiting times are. Therefore the strategy should be to increase the level of advanced drug preparation. However, until now we have assumed that reaching high levels of advanced preparation was possible. Yet this is not obvious. We now discuss the economic dimension of this problem, and the practicalities of advanced preparation, to answer the question: is it possible, and economically viable, to reach high levels of advanced preparation?

\section{DISCUSSION}

Figure 3 shows that advanced preparation is a superior solution compared to other measures when faced with the issue of waiting times due to long drug delivery lead times. After discussion with managers and physicians, a desirable course of action would be to first increase advanced preparation to $70 \%$ without modifying the list of products eligible to advanced preparation, and then to increase that list. To do so without spoiling drugs, or even more to do so whilst reducing the proportion of spoiled drugs, information must be gathered on the patient's state before preparing the drugs.

Many concepts can be imagined that would transmit information on patient status to the oncology unit and the pharmacy. Smartphone apps have already been used to follow on secondary effects of treatment, and patient acceptance is good (McCann et al. 2009). However, there are issues with this solution. The first one is that patients need to be equipped. Patients in Henri Mondor hospital seem to have a low smartphone equipment rate. The second issue is cost. The system needs to be developed (internally or externally), but it must also be integrated inside the existing IT system - a difficult task for a local app in the common IT environment of a 95,000 people hospital group. Finally, it is not sure that patients will regularly complete the form on their smartphone and that they will do it as seriously as when answering a professional in an oral conversation.

Another, more traditional concept is based on phone calls. Phone call platforms exist for different purposes in outpatient oncology: advanced drug preparation (Scotté et al. 2013) or management of secondary effects (Coriat et al. 2012). Such a platform can be created inside the hospital, or subcontracted to an external firm. In our context, subcontracting is a complex and long process. On the opposite, setting up a small cell that would call between 20 and 30 patients and labs every day is light solution. Based on feedback from other hospitals, one nurse is enough. Combined with existing IT systems, small spreadsheet based developments are enough to support this task.

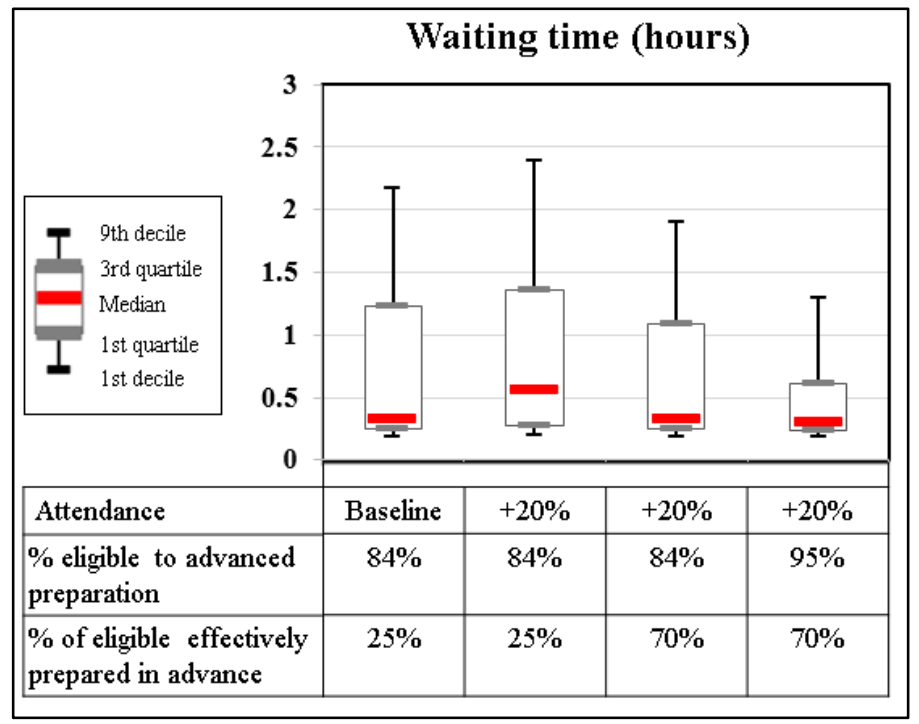

Figure 5: Effect of advanced preparation with a $20 \%$ increase of the number of patients. 


\section{Lamé, Jouini, Stal-Le Cardinal, Carvalho, Tournigand, and Wolkenstein}

The cost of such a solution (one nurse to call patients and medical labs before the day of chemotherapy) is quite low, around $50 \mathrm{k} € /$ year, the cost of one nurse. All other proposed measures (adding a nurse or a pharmacy dispenser, buying a an additional isolator) incurred costs but no benefit on waiting times. The only other interesting was to add someone for transporting the drugs, but the cost would be around $30 \mathrm{k} €$ for a much lower benefit.

However, spending $50 \mathrm{k} €$ to reduce patient waiting times is not very interesting for an hospital administrator: there needs to be a benefit to the organization. To evaluate this benefit, we have simulated the system with an additional $20 \%$ of patients, which represents one million euros of revenue. Figure 5 shows the results of that simulation. If nothing is done, a $20 \%$ increase in attendance will result in an increase of waiting times. By increasing advanced preparation from $25 \%$ to $70 \%$, without extending the list of eligible products, the system can maintain its current performance. By then increasing the list of products eligible to advanced preparation from $84 \%$ to $95 \%$ of the preparations, the performance is significantly improved: the third quartile decreases from 1 hour 15 minutes to 36 minutes, the ninth decile decreases from 2 hours 10 minutes to 1 hour 17 minutes. Therefore the proposed solution allows to accommodate $20 \%$ additional patients in better conditions. Other advantages are expected, but they are harder to quantify. Today, nurses and pharmacists spend a lot of time on the phone to coordinate drug preparation in real time. With advanced preparation, we hope to reduce this phenomenon and save time for nurses and pharmacists. This would also reduce stress for these two categories of staff.

Considering the results of the simulation study, interviews in other hospitals and the organization in which we work, we propose a two-step approach to reduce waiting times, that will in the same time increase the capacity of the outpatient clinic. The first step is to increase the proportion of drugs that are effectively prepared in advance. The second step is to enlarge the list of drugs that are eligible for advanced preparation. The reason for this sequencing lies in the fact that the logic behind these two steps is not the same.

For step one, the challenge is to have information on patient status soon enough to be able to prepare the drugs on treatment's eve or before. This information reduces the risk that a drug is prepared for a patient who is not in good-enough condition to receive it. For step two, enlarging the list of drugs that can be produced in advance, the financial risk must be finely evaluated as some drugs cost several thousand euros per dose. This can only come as a second step, because the availability of advanced information on patient status modifies the level of risk associated to advanced preparation. If you know more about your patient's status, then the risk of preparing drugs that will be spoiled is lower.

The first step deals with coordination of operational processes, the second step requires a policy adjustment from the pharmacy. As a consequence, methods for each step are different. For stage one, communication between patients, labs and the hospital is the key. For that we propose to have a nurse calling patients and labs before the day of chemotherapy. For stage two, risk assessment by the pharmacy is the core challenge. A separate study will be necessary to assess precisely which additional products can be prepared in advance. $95 \%$ is given here as an indicative value that we hope to reach. This ratio is very dependent on the patient mix, therefore it is difficult to extrapolate from other hospitals where we conducted interviews. Although $95 \%$ is an indicative value, there is no reason to believe that the current ratio could not be increased if a system to recover advanced information on patient status is created.

\section{CONCLUDING REMARKS}

This study is an example of a preliminary study prior to process redesign. However, contrary to many studies in healthcare management, its emphasis is on interactions and coordination between two hospital departments rather than on the optimization of units individually. In the present case, this approach proved to be very effective. The final proposition is a phone call platform to gather advanced information on patient status in order to allow drug preparation before the day of chemotherapy. This solution can help to divide waiting times by a factor of three for $75 \%$ of the patients, and bring $90 \%$ of the patients under $1 \mathrm{~h}$ of waiting rather than almost $2.5 \mathrm{~h}$. This solution is beyond comparison with other measures 


\section{Lamé, Jouini, Stal-Le Cardinal, Carvalho, Tournigand, and Wolkenstein}

based on re-staffing, which are the common demands of department managers. Noticing that managers spontaneously come up with unit-based solutions shows that silo-thinking is deeply rooted. To overcome this issue, cooperation must be created between departments and satisficing solutions will often have to be preferred to optimal ones, as internal politics and budgetary policies play an important role. Yet the results are worth the effort, as multi-department approaches can yield significant results.

In addition to the lack of multi-department models, some authors express a frustration with the fact that many simulation models in healthcare are facility-specific (Gunal and Pidd 2010). Our model does not go as far as being a general model for outpatient chemotherapy delivery. However, our interviews with oncology and pharmacy managers in French hospitals (five hospitals, both private and public, both integrated cancer care centers and general hospitals) have given us confidence that the conceptual model can be generalized to most French hospitals. Structural modifications to the conceptual model would bear on whether pharmacy isolators work with a batch sterilization-in and -out or batch sterilization-in and inline sterilization-out. This has an impact on preparation lead times. Other modifications would of course concern arrival patterns and patient mix. However, such variations are inherent to the fact that two different hospitals do not operate in the same context.

Going further, current recommendations in Germany (Deutsche Gesellschaft für Onkologische Pharmazie 2009), the United Kingdom (Turner, McCalla, and London Cancer New Drugs Group 2011) and from the European Society of Oncology Pharmacy (German Society of Oncology Pharmacy 2008) state that cytotoxic drug preparation should be performed in a centralized unit. Therefore the structure of the model would be applicable to the vast number of hospitals enforcing these recommendations and practicing advanced preparation. The first condition includes the majority of European hospitals with an activity in oncology. We do not know of existing data on the share of hospitals performing advanced preparation, however the literature reveals that besides France it is practiced in the Netherlands (Masselink et al. 2012). Concerning the rest of the world, most OR/OM articles on outpatient chemotherapy study US hospitals and do not mention advanced preparation.

The project presented in this article opens towards two main questions. The first one concerns the development of the phone call platform to gather patient information. Healthcare service design has its specificities, and co-design with patients is a promising approach (Bate and Robert 2006). The second way forward is the evaluation of the financial risk associated to the production in advance of a defined chemotherapy dose. Models have been proposed, e.g. (Masselink et al. 2012), but they do not take into account the impact of advanced information on the residual risk that the patient cannot receive her chemotherapy. To move forward and prepare more products in advance, including expensive, unstable products, we have to be able to quantify the risk we are taking. To do this we must assess the quality of the information gathered. Feedback from other hospitals gives us confidence that this information is valuable, but models of "value of information" would be useful. This new element has strong implications and should make it possible to prepare in advance products for which the risk is considered too high today.

\section{ACKNOWLEDGMENTS}

The authors wish to thank all people at Henri Mondor hospital who participated in this study, especially staff from the oncology and pharmacy units.

\section{REFERENCES}

Bate, P., and G. Robert. 2006. "Experience-Based Design: From Redesigning the System around the Patient to Co-Designing Services with the Patient." Quality and Safety in Health Care 15 (5): 30710. doi:10.1136/qshc.2005.016527.

Catania, C., T. De Pas, I. Minchella, F. De Braud, D. Micheli, L. Adamoli, G. Spitaleri, C. Noberasco, A . Milani, M. G. Zampino, F. Toffalorio, D. Radice, A. Goldhirsch and F. Nolè 2011. "'Waiting and the 
Waiting Room: How Do You Experience Them?' Emotional Implications and Suggestions from Patients with Cancer." Journal of Cancer Education 26 (2): 388-94. doi:10.1007/s13187-010-0057-2.

Coriat, R., P. Boudou-Rouquette, J.-P. Durand, P. Forgeot d'Arc, I. Martin, O. Mir, S. Ropert, J. Alexandre, and F. Goldwasser. 2012. "Cost Effectiveness of Integrated Medicine in Patients With Cancer Receiving Anticancer Chemotherapy." Journal of Oncology Practice 8 (4): 205-10. doi:10.1200/JOP.2011.000447.

Debreuve-Theresette, A., N. Jovenin, A. C. Stona, M. Kraïem-Leleu, F. Burde, D. Parent, D. Hettler, and J. B. Rey. 2015. "Programme d'évaluation de l'administration des chimiothérapies en hôpital de jour en Champagne-Ardenne (PEACH): satisfaction et délais d'attente des patients." Revue d'Épidémiologie et de Santé Publique, October. doi:10.1016/j.respe.2015.08.006.

DeSantis, C. E., C. C. Lin, A. B. Mariotto, R. L. Siegel, K. D. Stein, J. L. Kramer, R. Alteri, A. S. Robbins, and A. Jemal. 2014. "Cancer Treatment and Survivorship Statistics, 2014." CA: A Cancer Journal for Clinicians 64 (4): 252-71. doi:10.3322/caac.21235.

Deutsche Gesellschaft für Onkologische Pharmazie, ed. 2009. Qualitätsstandards für den pharmazeutisch-onkologischen Service mit Kommentar: QuapoS 4. 5th ed. Oldenburg: Onko-Press.

Dobish, R. 2003. "Next-Day Chemotherapy Scheduling: A Multidisciplinary Approach to Solving Workload Issues in a Tertiary Oncology Center." Journal of Oncology Pharmacy Practice 1 (9): $37-$ 42. doi:10.1191/1078155203jp105oa.

German Society of Oncology Pharmacy. 2008. "QuapoS 4 - Quality Standard for the Oncology Pharmacy Service with Commentary." European Society of Oncology Pharmacy (ESOP). http://www.esop.li/downloads/library/quapos4_english.pdf.

Gunal, M. M., and M. Pidd. 2010. "Discrete Event Simulation for Performance Modelling in Health Care: A Review of the Literature." Journal of Simulation 4 (1): 42-51.

Halpern, M. T., and K. Robin Yabroff. 2008. "Prevalence of Outpatient Cancer Treatment in the United States: Estimates from the Medical Panel Expenditures Survey (MEPS)." Cancer Investigation 26 (6): 647-51. doi:10.1080/07357900801905519.

Kallen, M. A., J. A. Terrell, P. Lewis-Patterson, and J. P. Hwang. 2012. "Improving Wait Time for Chemotherapy in an Outpatient Clinic at a Comprehensive Cancer Center." Journal of Oncology Practice 8 (1): e1-7. doi:10.1200/JOP.2011.000281.

Lamé, G., O. Jouini, and J. Stal-Le Cardinal. 2016. "Outpatient Chemotherapy Planning: A Literature Review with Insights from a Case Study." IIE Transactions on Healthcare Systems Engineering, May. doi:10.1080/19488300.2016.1189469.

Lau, P. K. H., M. J. Watson, and A. Hasani. 2014. "Patients Prefer Chemotherapy on the Same Day As Their Medical Oncology Outpatient Appointment.” Journal of Oncology Practice 10 (6): e380-84.

Lis, C. G., M. Rodeghier, and D. Gupta. 2009. "Distribution and Determinants of Patient Satisfaction in Oncology: A Review of the Literature." Patient Preference and Adherence 3: 287-304. doi:10.2147/PPA.S6351.

Masselink, I. H. J., T. L. C. van der Mijden, N. Litvak, and P. T. Vanberkel. 2012. "Preparation of Chemotherapy Drugs: Planning Policy for Reduced Waiting Times." Omega-International Journal of Management Science 40 (2): 181-87. doi:10.1016/j.omega.2011.05.003.

Mazier, A., J.-C. Billaut, and J.-F. Tournamille. 2010. "Scheduling Preparation of Doses for a Chemotherapy Service." Annals of Operations Research 178 (1): 145-54. doi:10.1007/s10479-0090624-2.

McCann, L., R. Maguire, M. Miller, and N. Kearney. 2009. "Patients' Perceptions and Experiences of Using a Mobile Phone-Based Advanced Symptom Management System (ASyMS@) to Monitor and Manage Chemotherapy Related Toxicity." European Journal of Cancer Care 18 (2): 156-64. doi:10.1111/j.1365-2354.2008.00938.x.

Sargent, R G. 2013. "Verification and Validation of Simulation Models." Journal of Simulation 7 (1): 12 24. doi:10.1057/jos.2012.20. 
Scotté, F., S. Oudard, H. Aboudagga, R. Elaidi, and B. Bonan. 2013. "A Practical Approach to Improve Safety and Management in Chemotherapy Units Based on the PROCHE - Programme for Optimisation of the Chemotherapy Network Monitoring Program." European Journal of Cancer 49 (3): 541-44. doi:10.1016/j.ejca.2012.08.025.

Soni, A. 2014. "Trends in Use and Expenditures for Cancer Treatment among Adults 18 and Older, U.S. Civilian Noninstitutionalized Population, 2001 and 2011." Statistical Brief \#443. Rockville, MD, USA: Agency for Healthcare Research and Quality. http://www.meps.ahrq.gov/mepsweb/data_files/publications/st443/stat443.pdf.

Turner, J., P. McCalla, and London Cancer New Drugs Group. 2011. "Pan London Guidelines for the Safe Prescribing, Handling and Administration of Systemic Anti Cancer Treatment Drugs." London, UK: London Cancer Networks. http://www.londoncanceralliance.nhs.uk/media/42575/panlondoncytopolicy_final_v1_01.pdf.

\section{AUTHOR BIOGRAPHIES}

GUILLAUME LAME is a PhD student at Laboratoire Genie Industriel, CentraleSupélec, France. He works in collaboration with Henri Mondor Hospital (Créteil, France) on mixed methodologies to improve outpatient chemotherapy planning. His email address is guillaume.lame@centralesupelec.fr.

OUALID JOUINI, PhD, is an Associate Professor in Operations Management at Laboratoire Génie Industriel, Ecole Centrale Paris. His current research interests are in stochastic modeling and service operations management. His main application area is call centers and healthcare systems.. His email address is oualid.jouini@centralesupelec.fr.

JULIE STAL-LE CARDINAL, PhD, is a Professor in the Industrial Engineering Laboratory (LGI) at Ecole Centrale Paris, France. Her research interest is to discover new methodologies of design and management in an industrial context. She works on team diversity and project management. Her email address is julie.le-cardinal@ centralesupelec.fr.

MURIEL CARVALHO, is pharmacist in pharmacy department of university Hospital Henri Mondor, France. She received a Pharm D degree from faculty of pharmacy Lyon in 2005. She is the head of chemotherapy preparation unit and clinical trials dispensing unit. Her email address is muriel.verlindecarvalho@aphp.fr.

CHRISTOPHE TOURNIGAND, MD PhD is Head of the Medical Oncology Department in Henri Mondor Hospital, Assistance Publique-Hôpitaux de Paris, France. He is a Professor at the Université Paris-Est Créteil. He is the co-author of more than 110 peer-reviewed publications. His clinical research interests are mainly in gastro-intestinal malignancies, but also in GU. His email address is christophe.tournigand@aphp.fr.

PIERRE WOLKENSTEIN, MD PhD, is Head of the Department Cancers Immunity Transplantation Infections at Henri Mondor Hospital, Assistance Publique-Hôpitaux de Paris, France. He is a Professor of dermatology at the Université Paris-Est Créteil. He is the co-author of more than 240 peer-reviewed publications. His fields of interest include cutaneous adverse drug reactions, genetics (neurofibromatoses) and cancers (malignant nerve sheath tumours), and acne and hidradenitis suppurativa (epidemiology and management). His email address is pierre.wolkenstein@aphp.fr. 